\title{
Bermain Vegetable Eating Motivation (Vem) terhadap Perilaku Makan Sayuran pada Anak Prasekolah
}

\author{
Islaeli Islaeli ${ }^{1 凶}$, Ari Nofitasari ${ }^{2}$, Sri Wulandari ${ }^{3}$ \\ Program Studi Keperawatan, Stikes Mandala Waluya Kendari \\ DOI: $\underline{10.31004 / \text { obsesi.v5i1.734 }}$
}

\begin{abstract}
Abstrak
Penelitian ini bertujuan untuk mengetahui pengaruh pemberian bermain vegetable eating motivation (VEM) terhadap perilaku makan sayur pada anak prasekolah di TK Asma Jaya Kecamatan Lasolo Kabupaten Konawe Utara. Jenis penelitian ini adalah eksperimental dengan pendekatan pre and post test without control. Populasi penelitian adalah seluruh anak prasekolah TK Asma Jaya Kecamatan Lasolo Kabupaten Konawe Utara yang berjumlah 16 anak. Teknik pengambilan sampel menggunakan total sampling, metode analisis menggunakan Uji Wilcoxon. Penelitian ini dilaksanakan pada bulan Juli-Agustus 2018. Hasil penelitian menunjukkan bahwa ada pengaruh pemberian bermain VEM terhadap perilaku makan sayur pada anak prasekolah di TK Asma Jaya Kabupaten Konawe Utara. Diharapkan kepada orang tua agar dapat memberikan gambaran tentang cara pemberian motivasi dan edukasi pada anak dengan pendekatan bermain VEM agar anak memiliki perilaku makan sayur yang baik.
\end{abstract}

Kata Kunci : vegetable eating motivation; perilaku makan sayur; anak prasekolah

\begin{abstract}
This study aims to determine the effect of playing vegetable eating motivation (VEM) on vegetable eating behavior in preschool children at Asma Jaya Kindergarten, Lasolo District, Konawe Utara Regency. The research is experimental with a pre and post test approach without control. The study population was all preschool children Asma Jaya Kindergarten, Lasolo District, North Konawe Regency, totaling 16 children. The sampling technique used total sampling, the method of analysis used the Wilcoxon test. This research was conducted in July-August 2018. The results showed that there was an effect of playing VEM on vegetable eating behavior in preschool children at Asma Jaya Kindergarten, Konawe Utara Regency. It is hoped that parents can provide an overview of how to provide motivation and education to children with the VEM play approach so that children have good vegetable eating behavior.
\end{abstract}

Keywords: vegetable eating motivation; vegetable eating behavior; preschool children

Copyright (c) 2020 Islaeli Islaeli, Ari Nofitasari, Sri Wulandari

$\triangle$ Corresponding author : Islaeli

Email Address : islaelimwkdi@gmail.com (Kendari, Sulawesi Tenggara, Indonesia)

Received 29 August 2020, Accepted 4 September 2020, Published 8 September 2020 


\section{PENDAHULUAN}

Anak usia dini yaitu anak yang sedang berada dalam pertumbuhan dan perkembangan yang pesat baik itu fisik atau psikis serta anak-anak yang berusia dibawah 6 tahun. Jadi mulai dari anak lahir hingga ia mencapai umur 6 tahun ia akan dikategorikan sebagai anak usia dini. Menurut Piaget dalam Sumantri anak usia dini berada pada masa lima tahun pertama yang disebut The Golden Age. Masa ini merupakan masa emas perkembangan anak (Nurdin \& Anhusadar, 2020). Untuk mewadahi perkembangan anak perlu lembaga Pendidikan yang menstimulus perkembangan anak sejak usia dini seperti Lembaga PAUD sehingga perkembangan anak dapat dikembangkan sesuai usia anak. Menurut Musfiroh bahwa pendidikan Anak Usia Dini merupakan pendidikan yang diselenggarakan untuk mengembangkan keterampilan yang merupakan pendidikan dasar serta mengembangkan diri secara utuh sesuai dengan asas pendidikan sedini mungkin dan sepanjang hayat. Aspek yang dikembangkan dalam pendidikan anak usia dini adalah aspek pengembangan pembiasaan meliputi sosial, emosi, kemandirian, moral, dan nilai-nilai agama, serta pengembangan kemampuan dasar yang meliputi pengembangan bahasa, kognitif, dan fisik motoric (Suriati, Kuraedah, Erdiyanti, \& Anhusadar, 2019). Salah satu bentuk lembaga pendidikan anak usia dini yang berada pada jalur formal adalah taman kanak-kanak (TK) yang berusia 5-6 tahun.

Tujuan pendidikan di TK untuk pencapaian perkembangan yaitu: Nilai agama dan moral, fisik motorik kasar, motorik halus, kesehatan fisik, kognitif yaitu pengetahuan umum dan sains, konsep bentuk warna ukuran dan pola, konsep bilangan lambang bilangan dan huruf, bahasa yaitu menerima bahasa, mengungkapkan bahasa, keaksaraan, sosioal emosional. Kreativitas anak usia dini dapat diupayakan melalui permainan yang dirancang oleh Pendidik di Lembaga PAUD, karena dengan permainan anak dapat mengembangkan serta mengintergrasikan semua potensinya, sehinga mereka lebih kreatif. Peran Pendidik dalam kegiatan permainan anak adalah memberikan dorongan, membimbing bermain bagi anak dan membantu anak mengembangkan potensinya, sehingga mereka menjadi anak yang kreatif (L. O. Anhusadar \& Islamiyah, 2020).

Usia prasekolah (3-6 tahun) disebut juga masa keemasan (the golden years), yang hanya datang sekali dan tidak dapat diulangi lagi, yang sangat menentukan untuk pengembangan kualitas manusia (Suryana, 2007). Anak prasekolah merupakan masa dimana anak mulai peka dan sensitif untuk menerima berbagai rangsangan. Pada masa inilah anak dengan mudah menerima stimulasi dari lingkungannya sebagai dasar untuk mengembangkan kemampuan kognitif, bahasa, motorik, nilai moral, dan sosial emosional pada anak usia dini (Masganti Sit, 2015). Untuk mengembangkan 5 aspek tersebut tentunya asupan nutrisi (gizi) sangat mendukung dalam pertumbuhan dan perkembangan anak (Sujiono, 2015). MDG's (Millenium Development Goals) merupakan salah satu tujuan dimana pada tahun 2015 setiap negara harus berupaya terus untuk menurunkan separuh jumlah penduduk miskin dan kelaparan yang juga terdampak pada kesehatan gizi anak-anak. Asupan makanan yang tidak sesuai dengan kebutuhan tubuh akan memicu masalah gizi yang nantinya berdampak pada rentannya tubuh terhadap penyakit dan hal ini sering terjadi di daerah atau negara berkembang.

Di Indonesia pencapaian MDG's dengan indicator indikator paling menentukan untuk memberantas kemiskinan dan kelaparan adalah prevelensi gizi kurang dan gizi buruk. Adanya penurunan untuk prevalensi gizi kurang menurun secara signifikan di tahun 1989 dari $31 \%$ menjadi $17,9 \%$ di tahun 2010 . Demikian pula prevalensi gizi buruk menurun dari 12,8\% (1995) menjadi 4,9\% (2010). Kecenderungan ini menunjukan target penurunan prevalensi gizi kurang dan gizi buruk menjadi 15\% dan 3,5\% pada tahun 2015 ini dapat tercapai (Amirullah, Try, Putra, Daud, \& Kahar, 2020).

Menurut beberapa ahli keperawatan diantaranya Paplau $\mathrm{H}$ mengatakan bahwa kesehatan adalah proses yang berlangsung mengarah kepda kretifitas, konstruktif, dan produktif. Dengan demikian bahwa kesehatan adalah suatu hal yang tidak dapat dianggap 
sepele keberadaannya dalam membentuk sumber daya manusia yang unggul. Bidang kesehatan perlu mendapatkan perlakuan dan perhatian khusus guna menunjang kepentingan pembangunan karakter bangsa (Udu, Anhusadar, Alias, \& Ali, 2019). Kebutuhan nutrisi merupakan kebutuhan yang sangat penting dalam membantu proses pertumbuhan dan perkembangan anak serta dapat mencegah terjadinya berbagai penyakit akibat kurang nutrisi dalam tubuh. Oleh sebab itu, makanan yang dikonsumsi anak sebaiknya beraneka ragam dan mengandung berbagai vitamin.

Dalam pertumbuhan anak diperlukan gizi yang seimbang, supaya seluruh anggota badan dapat tumbuh secara wajar, pertumbuhan otot dan tulang dapat kuat, dan sehat. Beberapa sumber gizi yang sangat berguna tersebut terkandung di dalam sayuran (Sukamti, 1994) (Hermina \& S, 2016). Sayuran merupakan sumber vitamin, mineral, dan kaya akan serat yang sangat mudah ditemukan di dalam bahan makanan. Mengkonsumsi makanan berserat sangat baik karena dapat membantu memperlancar proses pencernaan didalam tubuh, mempengaruhi peningkatan ukuran, berat, dan melunakkan feses (Kusharto, 2007).

Karena pentingnya konsumsi buah dan sayur, organisasi pangan dan pertanian dunia Food and Agriculture Organization (FAO), merekomendasikan warga dunia untuk makan sayur dan buah secara teratur sebanyak $75 \mathrm{~kg} / \mathrm{kapita} /$ tahun begitupun dengan World Health Organization (WHO) merekomendasikan agar konsumsi sayur dan buah sebanyak 400 gram setiap hari (Indira, 2015). Data WHO menunjukkan bahwa kasus anak usia prasekolah underweight di dunia sebesar $15,7 \%$ dan anak usia prasekolah overweight sebanyak $6,6 \%$ (WHO, 2013). Secara nasional, prevalensi berat-kurang pada tahun 2013 adalah 19,6\%, terdiri dari 5,7\% gizi buruk dan 13,9\% gizi kurang (Balitbang Kemenkes, 2013). Berdasarkan data Riset Kesehatan Dasar (Riskesdas) Tahun 2013 menyatakan bahwa tingkat konsumsi sayur pada anak prasekolah di Indonesia 35 kilogram per kapita per tahun. Angka itu jauh lebih rendah dengan angka konsumsi sayuran yang dianjurkan 75 kilogram per kapita per tahun (Khalimatus Sa'diya, 2016).

Menurut Soetjiningsih kebutuhan gizi, memberikan makanan yang benar pada anak harus dilihat dari banyak aspek, seperti ekonomi, sosial, budaya, agama, disamping aspek medik dari anak itu sendiri. Makanan pada anak usia dini harus serasi, selaras dan seimbang. Serasi artinya sesuai dengan tingkat tumbuh kembang anak. Selaras adalah sesuai dengan kondisi ekonomi, sosial budaya serta agama dari keluarga. Sedangkan seimbang artinya nilai gizinya harus sesuai dengan kebutuhan berdasarkan usia dan jenis bahan makanan seperti karbohidrat, protein dan lemak (Laode Anhusadar, 2020).

Salah satu penyebab rendahnya konsumsi sayur pada anak karena kurangnya pengetahuan dan sikap mengabaikan pentingnya makan sayur (Indira, 2015). Tidak efektifnya pendidikan gizi pada anak semenjak usia dini berdampak pada pengetahuan yang kurang tentang pola konsumsi makanan yang sehat dan seimbang saat dewasa, sehingga menyebabkan perilaku yang salah (Kemenkes, 2014). Masalah tersebut dapat berakibat buruk bagi tumbuh kembang anak. Anak dapat mempunyai peluang besar untuk menderita kurang gizi karena makanan yang dikonsumsi dalam jumlah sedikit sehingga tidak memenuhi kebutuhan nutrisinya (Arifin, 2016). Selain itu, anak dapat mengalami stunting atau menjadi balita pendek (KemenkesRI, 2016). Berdasarkan Riset Kesehatan Dasar tahun 2013, Indonesia dengan prevalensi anak balita pendek sebesar 35,6\% merupakan negara ke-5 terbesar yang berkontribusi pada $90 \%$ stunting di dunia. Anak pendek mempunyai risiko lebih tinggi menderita diabetes, obesitas, hipertensi dan stroke pada usia dewasa (Kemenkes, 2014). Selain itu, Konstipasi juga menjadi salah satu penyakit yang akan dialami bila anak kurang mengkonsumsi sayur.

Bermain secara tidak langsung akan membuat anak mengembangkan kemampuan kognitif, fisik, motorik, sosial, dan emosionalnya. Oleh karena itu memberikan stimulus dengan pendekatan permainan kepada anak usia prasekolah merupakan hal yang sangat penting yang harus dilakukan (Hasanah, 2016). Dalam Pendidikan Anak Usia dini ( PAUD ),bermain sambil belajar merupakan kegiatan yang baik untuk anak. Bermain adalah setiap 
kegiatan yang dilakukan untuk kesenangan yang ditimbulkan tanpa pertimbangan hasil akhir. Melalui bermain anak akan memiliki berbagai manfaat bagi perkembangan, aspek ini saling menunjang satu sama lain dan tidak dapat dipisahkan. Apabila satu aspek tidak diberikan kesempatan untuk berkembang, maka akan terjadi ketimpangan karena bermain adalah aktivitas yang menyenangkan dan merupakan kebutuhan yang sudah melekat dalam diri anak (L. Anhusadar, 2016).

Beberapa penelitian telah dilakukan untuk melihat pengaruh bermain untuk meningkatkan minat makan sayuran bagi anak usia prasekolah, salah satunya dengan bermain storytelling efektif meningkatkan pengetahuan dan sikap dalam mengkonsumsi sayur pada anak usia prasekolah (Ilya Krisnana, Yuni Sufyanti Arief, 2015). Penelitian lain menyimpulkan bahwa Kedua bermain peran mikro tersebut sama-sama memiliki pengaruh dalam kecerdasan interpersonal anak, namun bermain peran mikro bebas memberikan hasil lebih baik dalam kegiatan pembelajaran yang dilakukan dibandingkan bermain peran mikro tepimpin. Dengan demikian, hal ini merupakan bukti empiris bahwa kecerdasan interpersonal anak yang diberikan bermain peran mikro bebas lebih tinggi dibandingkan anak yang diberikan bermain peran mikro terpimpin. Maka dapat direkomendasikan bahwa bermain peran mikro bebas lebih cocok diterapkan dalam Kecerdasan interpersonal (Damayanti, Ch, \& Hapidin, 2018).

Penelitian yang dilakukan oleh (Wahyuni, Syukri, \& Halida, 2017) yang berjudul "Peningkatan motivasi anak makan sayuran melalui metode bermain permainan cooking class pada anak usia 4-6 tahun" menemukan bahwa, melalui metode bermain permainan cooking class dapat meningkatkan motivasi anak makan sayuran pada anak usia 4-6 tahun di RA AL- Muhajirin Rasau Jaya, Kabupaten Kubu Raya, Provinsi Kalimantan Barat. Vegetable Eating Motivation (VEM) merupakan salah satu bentuk permainan yang dirancang oleh peneliti dengan tujuan memberikan motivasi dan edukasi kepada anak prasekolah dengan pendekatan bermain yang dilakukan dalam bentuk rangkaian permainan dan dilakukan selama 6 hari, dengan tujuan untuk meningkatkan perilaku makan sayuran pada anak prasekolah.

Berdasarkan hasil observasi awal kepada 16 orang anak prasekolah di TK Asma Jaya Kecamatan Lasolo Kabupaten Konawe Utara, 100 \% Ibu selalu menghidangkan menu sayur setiap hari. Akan tetapi, 11 Anak diantaranya menolak untuk memakan sayur, Anak lebih memilih nasi dan lauk saja seperti telur, ikan dan ayam. Anak yang menolak makan sayuran mengatakan tidak menyukai sayuran karena rasanya yang pahit, hambar, teksturnya lama dikunyah, Peneliti juga melakukan wawancara kepada 10 orang ibu dari anak prasekolah di TK Asma Jaya 8 orang ibu mengatakan anaknya sulit jika disuruh makan sayur, 2 orang ibu mengatakan anaknya mau makan sayuran. Melihat perilaku anak prasekolah yang jarang sekali suka dengan sayuran dan hari-hari mereka dipenuhi dengan bermain, maka dibutuhkanlah sebuah terapi dengan pendekatan bermain yang dapat memotivasi dan meningkatkan konsumsi sayuran pada anak prasekolah. Berdasarkan uraian diatas, peneliti tertarik untuk mengadakan penelitian tentang pengaruh bermain vegetable eating motivation (VEM) terhadap perilaku makan sayuran pada anak prasekolah di TK Asma Jaya Kecamatan Lasolo Kabupaten Konawe Utara.

Vegetable Eating Motivation (VEM) merupakan salah satu bentuk terapi bermain yang dirancang oleh peneliti dengan tujuan memberikan motivasi dan edukasi kepada anak prasekolah dengan pendekatan bermain yang dilakukan dalam bentuk rangkaian permainan dan dilakukan selama 6 hari, dengan tujuan untuk meningkatkan perilaku makan sayuran pada anak prasekolah. Vegetable Eating Motivation (VEM) merupakan salah satu bentuk terapi bermain yang bertujuan memberikan motivasi dan edukasi kepada anak prasekolah dengan pendekatan bermain untuk meningkatan perilaku makan sayuran pada anak prasekolah. Tahapan pelaksanaan bermain Vegetable Eating Motivation (VEM) peneliti lakukan sebagai berikut: 
Tabel Tahapan pelaksanaan bermain Vegetable Eating Motivation (VEM)

\begin{tabular}{|c|c|}
\hline Tujuan & 1. Meningkatkan citra diri sebagai layaknya manusia \\
\hline Bermain & 2. Dapat bersosialisasi dan berkomunikasi dengan teman sebaya \\
\hline Vegetable & 3. Untuk mengetahui lebih banyak tentang sayuran \\
\hline Eating & 4. Untuk mengetahui manfaat tentang sayuran \\
\hline Motivation & 5. Dapat mewarnai gambar yang disukainya \\
\hline Persiapan & $\begin{array}{l}\text { 1. Guru, orang tua, dan Anak diberitahu tujuan bermain } \\
\text { 2. Melakukan kontrak waktu } \\
\text { 3. Anak tidak rewel }\end{array}$ \\
\hline Peralatan & $\begin{array}{l}\text { 1. Alat mengambar (Pensil, Warna) } \\
\text { 2. Sketsa gambar sayuran }\end{array}$ \\
\hline $\begin{array}{l}\text { Prosedur } \\
\text { pelaksanaan }\end{array}$ & 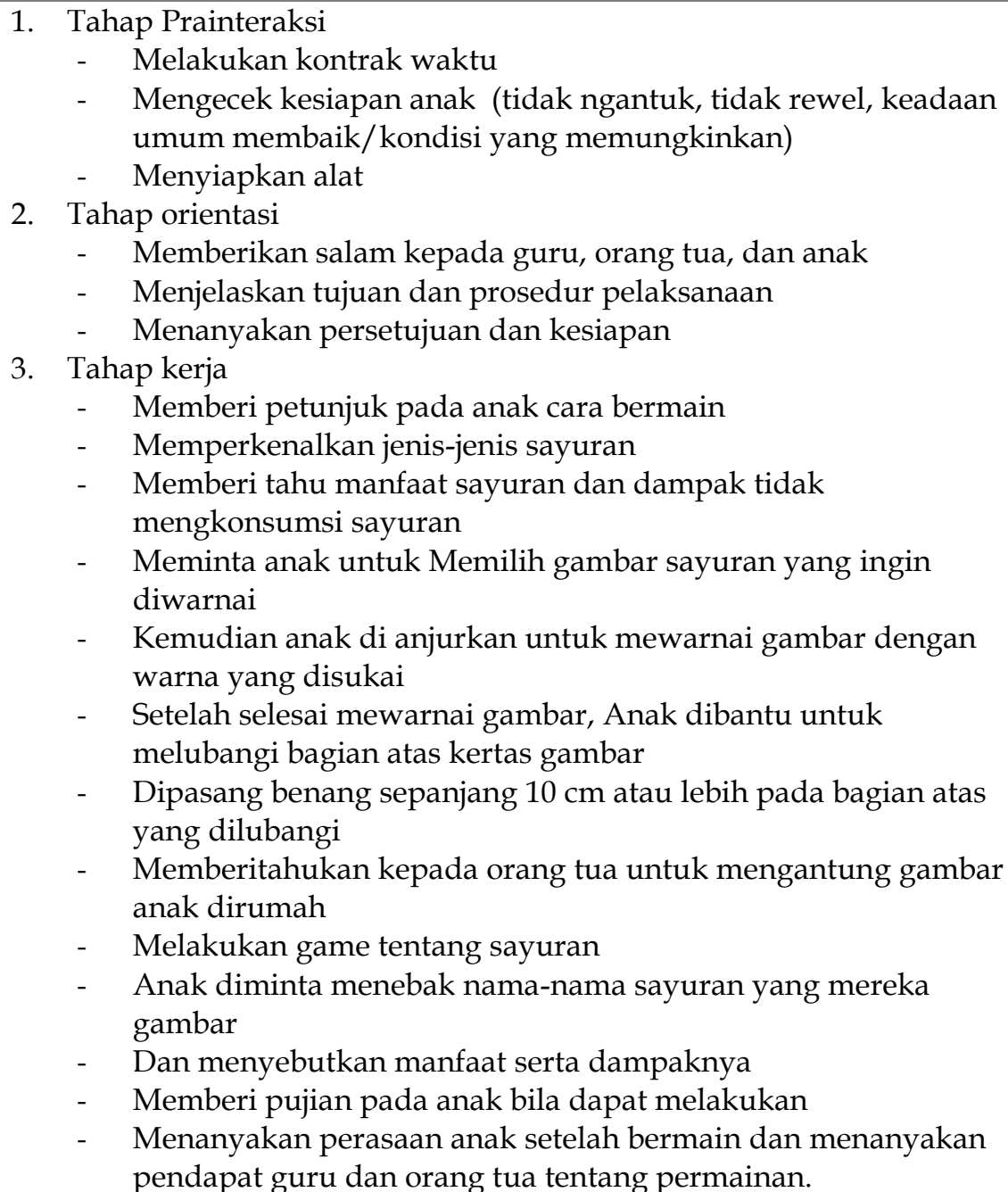 \\
\hline $\begin{array}{l}\text { Tahap } \\
\text { terminasi }\end{array}$ & $\begin{array}{l}\text { 1. Berpamitan dengan guru, orang tua, dan anak } \\
\text { 2. Membereskan kembali alat yang telah dipakai } \\
\text { 3. Mencuci tangan. }\end{array}$ \\
\hline
\end{tabular}

\section{METODOLOGI}

Jenis penelitian yang digunakan adalah penelitian kuantitatif dengan desain penelitian eksperimental dengan pendekatan pre and post test without control. Efektifitas perlakuan dinilai dengan cara membandingkan nilai pre test dengan post test. Sampel pada penelitian ini diobservasi terlebih dahulu sebelum diberi perlakuan, kemudian setelah diberi perlakuan sampel tersebut diobservasi kembali (Notoatmodjo, 2012). Perilaku makan sayur anak prasekolah diukur dengan menggunakan FFQ (Food Frequncy Questionnaire) yang dilakukan 
sebelum dan sesudah intervensi bermain vegetable eating motivation dan pemberian sketsa gambar sayuran. Kegiatan bermain dilakukan selama enam hari dan dilakukan pengukuran. Populasi dalam penelitian ini adalah seluruh anak prasekolah TK Asma Jaya Kecamatan Lasolo Kabupaten Konawe Utara yang berjumlah 16 anak dan dengan teknik total sampling. Teknis pengumpulan data adalah dokumentasi, wawancara dan observasi.

Prilaku makan sayur anak prasekolah diukur sebelum dan sesudah dilakukan metode bermain vegetable eating motivation (vem) dengan metode ceramah dan dan pemberian sketsa gambar sayuran. Dengan rancangan penelitian sebagai berikut.

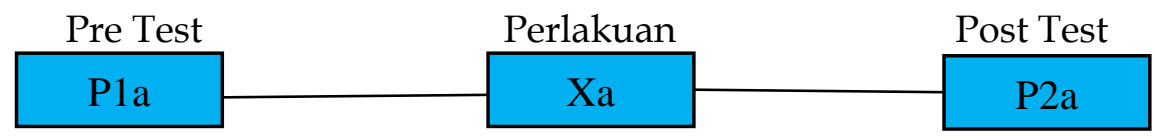

Keterangan :

P1a : Perilaku makan sayur sebelum pemberian terapi vegetable eating motivation (pre test)

$\mathrm{Xa}$ : Perlakuan (Terapi bermain vegetable eating motivation)

P2a : Perilaku makan sayur sesudah pemberian terapi vegetable eating motivation (post test)

Penelitian ini digambarkan dalam bentuk bagan berikut.

Variabel Independen

Bermain vegetable eating motivation
Variabel Dependen

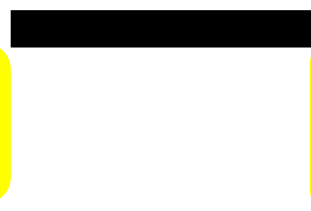

Perilaku makan sayur

\section{Gambar 1. Bagan Kerangka Konsep Penelitian}

Keterangan :

Perilaku Makan Sayur : Variabel dependen

Bermain vegetable eating motivation : Variabel independent

\section{HASIL DAN PEMBAHASAN}

Karakteristik responden meliputi umur dan jenis kelamin responden. Setiap karakteristik responden, distribusi responden menurut umur terlihat pada tabel berikut :

Tabel 1. Distribusi Kelompok Umur Responden Anak Pra Sekolah di TK Asma Jaya Kabupaten Konawe Utara

\begin{tabular}{cccc}
\hline No & Umur & N & $\%$ \\
\hline 1 & 4 tahun & 6 & 37,5 \\
\hline 2 & 5 tahun & 7 & 43,8 \\
\hline 3 & 6 tahun & 3 & 18,8 \\
\hline \multicolumn{4}{c}{ Jumlah } \\
\hline \multicolumn{2}{c}{ Sumber : Data Primer, 2018} \\
\hline
\end{tabular}

Tabel 1 menunjukkan bahwa dari 16 responden, terbanyak adalah umur 5 tahun sebanyak 7 responden $(43,8 \%)$ dan yang terkecil adalah umur 6 tahun yaitu sebanyak 3 responden $(18,8 \%)$.

Distribusi responden menurut jenis kelamin, terlihat pada tabel berikut: 
Tabel 2. Distribusi Kelompok Jenis Kelamin Responden Anak Pra Sekolah di TK Asma Jaya Kabupaten Konawe Utara

\begin{tabular}{cccc}
\hline No & Jenis Kelamin & $\mathbf{N}$ & $\mathbf{0}$ \\
\hline 1 & Laki-Laki & 7 & 43,8 \\
\hline 2 & Perempuan & 9 & 56,2 \\
\hline & Jumlah & $\mathbf{1 6}$ & $\mathbf{1 0 0}$ \\
\hline
\end{tabular}

Sumber : Data Primer, 2018

Tabel 2 menunjukkan bahwa dari 16 responden terdapat 7 responden $(43,8 \%)$ yang berjenis kelamin laki-laki dan terdapat 9 responden $(56,2 \%)$ yang berjenis kelamin perempuan.

Distribusi responden berdasarkan perilaku makan sayur pre test dapat terlihat pada tabel berikut :

Tabel 3. Distribusi Responden Perilaku Makan Sayur Pre Test di TK Asma Jaya Kabupaten Konawe Utara

\begin{tabular}{cccc}
\hline No & Perilaku Makan Sayur Pre Test & $\mathbf{N}$ & $\mathbf{0}$ \\
\hline 1 & Cukup & 2 & 12,5 \\
\hline 2 & Kurang & 14 & 87,5 \\
\hline & Jumlah & $\mathbf{1 6}$ & $\mathbf{1 0 0}$ \\
\hline
\end{tabular}

Sumber : Data Primer, 2018

Tabel 3 menunjukkan bahwa sebelum diberikan terapi bermain Vegetable Eating Motivation (VEM) dari 16 responden, terdapat 2 responden $(12,5 \%)$ yang memiliki perilaku makan sayur cukup dan terdapat 14 responden $(87,5 \%)$ yang memiliki perilaku makan sayur kurang. Sedangkan distribusi responden berdasarkan perilaku makan sayur post test dapat terlihat pada tabel berikut :

Tabel 4. Distribusi Responden Perilaku Makan Sayur Post Test di TK Asma Jaya Kabupaten Konawe Utara

\begin{tabular}{lllc}
\hline No & Perilaku Makan Sayur Post Test & $\mathbf{N}$ & $\mathbf{0}$ \\
\hline 1 & Cukup & 15 & 13,8 \\
\hline 2 & Kurang & 1 & 6,3 \\
\hline & Jumlah & $\mathbf{1 6}$ & $\mathbf{1 0 0}$ \\
\hline & \multicolumn{2}{c}{ Sumber : Data Primer, 2018}
\end{tabular}

Tabel 4 menunjukkan bahwa setelah diberikan terapi bermain Vegetable Eating Motivation (VEM) dari 16 responden, terdapat 15 responden $(93,8 \%)$ yang memiliki perilaku makan sayur cukup dan terdapat 1 responden $(6,3 \%)$ yang memiliki perilaku makan sayur kurang. Pada uji normatitas data dalam penelitian ini adalah sesuai tebel berikut ini:

Tabel 5. Uji normalitas data dengan menggunakan Shapiro-Wilk

\begin{tabular}{lllllll}
\hline \multicolumn{7}{c}{ Tests of Normality } \\
\hline & \multicolumn{7}{l}{ Kolmogorov-Smirnov } & \multicolumn{4}{l}{ Shapiro-Wilk } \\
\cline { 2 - 7 } Pre_test & .278 & 16 & .002 & .871 & 16 & .028 \\
\cline { 2 - 7 } Statistic & $\mathrm{df}$ & Sig. & Statistic & Df & Sig. \\
\hline Post_test & .204 & 16 & .075 & .906 & 16 & .100 \\
\hline
\end{tabular}

Tabel 5 menunjukkan bahwa hasil uji normalitas data menggunakan uji Shapiro-Wilk pada variabel perilaku makan sayur pre test menunjukkan bahwa nilai $p$ value $(0,028)<a$ $(0,05)$, dan variabel perilaku makan sayur post test menunjukkan bahwa nilai $p$ value $(0,100)$ 
$>$ a $(0,05)$ sehingga dapat disimpulkan bahwa data berdistribusi tidak normal. Karena data berdistribusi tidak normal maka menggunakan uji Wilcoxon.

\begin{tabular}{ll}
\hline Test Statistics & \\
\hline & post_test - pre_test \\
\hline$Z$ & $-3.455^{\mathrm{b}}$ \\
\hline Asymp. Sig. (2-tailed) & .001 \\
\hline
\end{tabular}

Berdasarkan hasil analisis uji Wilcoxon diperoleh nilai $\mathrm{p}$ value $=0,001<0,05$ maka Ho ditolak dan Ha diterima berati ada pengaruh pemberian bermain vegetable eating motivation (VEM) terhadap perilaku makan sayur pada anak prasekolah di TK Asma Jaya Kabupaten Konawe Utara.

Uji normalitas data dilakukan untuk mengetahui distribusi data, apakah data tersebut berdistribusi normal atau tidak yang akan menentukan jenis uji yang akan digunakan dalam melakukan analisis. Untuk lebih jelasnya dapat disajikan pada tabel uji normalitas di bawah ini.

Tabel 6 : Hasil Uji Normalitas Perilaku Makan Sayur Sebelum dan Sesudah Diberikan Terapi Bermain Vegetable Eating Motivation (VEM)

\begin{tabular}{c|c|c}
\hline Variabel Penelitian & P value & a \\
\hline Perilaku makan sayur pre test & 0,168 & 0,05 \\
\hline Perilaku makan sayur post test & 0,520 & 0,05 \\
\hline
\end{tabular}

Data primer diolah 2018

Tabel 6 menunjukkan bahwa hasil uji normalitas data menggunakan uji KolmogorovSmirnov pada variabel perilaku makan sayur pre test menunjukkan bahwa nilai $\mathrm{p}$ value $(0,168)>$ a $(0,05)$, dan variabel perilaku makan sayur post test menunjukkan bahwa nilai $p$ value $(0,520)>a(0,05)$ sehingga dapat disimpulkan bahwa data berdistribusi normal. Karena data berdistribusi normal maka memenuhi syarat untuk dilakukan uji Paired T Test.

Pengaruh pemberian bermain vegetable eating motivation (VEM) terhadap perilaku makan sayur pada anak prasekolah di TK Asma Jaya Kecamatan Lasolo Kabupaten Konawe Utara. Distribusi pengaruh pemberian bermain vegetable eating motivation (VEM) terhadap perilaku makan sayur pada anak prasekolah di TK Asma Jaya Kecamatan Lasolo Kabupaten Konawe Utara, yaitu:

Tabel 7. Analisis pengaruh pemberian bermain vegetable eating motivation (VEM) terhadap perilaku makan sayur pada anak prasekolah di TK Asma Jaya Kabupaten Konawe Utara

\begin{tabular}{cccccc}
\hline $\begin{array}{c}\text { Perilaku makan } \\
\text { sayur }\end{array}$ & n & Mean & SD & t value & P value \\
\hline Pre Test & 16 & 1,69 & 0,793 & \multirow{2}{*}{8,777} & 0,000 \\
\hline Post Tes & 16 & 4,56 & 1,209 & & \\
\hline & & Sumber : Data Primer, 2018 & &
\end{tabular}

Tabel 8 menunjukkan bahwa perilaku makan sayur pada pre tes memiliki nilai mean 1,69 dengan nilai SD 0,793. Sedangkan pada post tes memiliki nilai mean 4,56 dengan nilai SD 1,209. Berdasarkan hasil analisis uji paired $t$-test diperoleh nilai $t$ hit $=8,777$ dengan taraf kepercayaan 95\% $(0,05) \mathrm{df}=15$ diperoleh $\mathrm{t}$ tabel $(1,753)$. Jadi $\mathrm{t}$ hit $>\mathrm{t}$ tabel dan $\mathrm{p}$ value $=0,000$ $<0,05$ maka Ho ditolak dan Ha diterima berati ada pengaruh pemberian bermain vegetable eating motivation (VEM) terhadap perilaku makan sayur pada anak prasekolah di TK Asma Jaya Kabupaten Konawe Utara. 
Sayuran memiliki banyak manfaat yang baik bagi kesehatan. Mengonsumsi sayuran dan buah sangat bermanfaat untuk memenuhi kebutuhan gizi (Aswatini, Noveria, \& Fitranita, 2008). Hasil penelitian menunjukkan bahwa sebelum diberikan terapi bermain Vegetable Eating Motivation (VEM) dari 16 responden, terdapat 2 responden $(12,5 \%)$ yang memiliki perilaku makan sayur cukup dan terdapat 14 responden $(87,5 \%)$ yang memiliki perilaku makan sayur kurang. Hal ini menunjukkan bahwa banyak anak yang kurang mengkonsumsi sayur. Hal ini sesuai dengan teori bahwa pada masa usia prasekolah anak mengalami penurunan nafsu makan dan hanya mau makan makanan yang disukai (Siti Aizah, 2003). Siswa yang kurang mengkonsumsi sayur dikarenakan beberapa faktor seperti anak tidak suka dengan rasa sayur yang kurang enak, tidak suka dengan aroma sayur, serta model penyajian sayur yang kurang disukai oleh anak. Selain itu masih banyak juga anak yang kurang mengetahui tentang manfaat mengkonsumsi sayuran. Hal ini sesuai dengan teori bahwa pada masa usia prasekolah anak mengalami penurunan nafsu makan dan hanya mau makan makanan yang disukai. Orang tua harus berusaha keras memaksa anak untuk mau makan sayuran sehingga membuat suasana makan tidak nyaman dan anak menjadi rewel. Sikap ini merupakan suatu kasus global dan merupakan suatu kesulitan bagi orang tua untuk memberi anak mereka makanan yang mengandung serat dan banyak vitamin yaitu sayur mayur (Asy'ariyah, Arief, \& Krisnana, 2014).

Selanjutnya setelah diberikan terapi bermain Vegetable Eating Motivation (VEM) dari 16 responden, terdapat 15 responden $(93,8 \%)$ yang memiliki perilaku makan sayur cukup dan terdapat 1 responden $(6,3 \%)$ yang memiliki perilaku makan sayur kurang. Hal ini menunjukkan bahwa terjadi peningkatan jumlah anak yang signifikan dalam hal perilaku mengkonsumsi sayur setelah diberikan terapi bermain VEM oleh peneliti. Hal ini dapat disebabkan oleh pemberian terapi VEM yang disukai dan diminati oleh anak prasekolah sehingga banyak siswa yang antusias dalam mengikuti kegiatan yang diadakan oleh peneliti. Anak yang antusias dikarenakan belum pernah mendapatkan kegiatan mewarnai gambar sayuran sebelumnya, serta model gambar yang menarik sehingga anak suka dengan kegiatan menggambar sayuran. Peneliti juga menjelaskan kepada siswa tentang manfaat mengkonsumsi setiap sayuran dan akibat tidak mengkonsumsi jenis sayuran yang digambar oleh siswa. Sayur dan buah merupakan pangan yang mudah diperoleh di Indonesia, dan sangat bermanfaat bagi tubuh, karena kaya akan zat gizi, seperti vitamin, mineral, dan serat untuk mengatur proses pencernaan dalam tubuh. Di Indonesia menyarankan untuk mengkonsumsi sayur sebanyak 3-5 porsi dan buah-buahan 2-3 porsi dalam sehari. WHO menyarankan konsumsi sayur dan buah-buahan sebanyak 400 gram setiap hari (Rahmad \& Almunadia, 2017).

Menurut peneliti bahwa adanya peningkatan jumlah anak prasekolah setelah diberikan terapi bermain VEM disebabkan oleh beberapa faktor yaitu terapi yang diberikan secara berkelompok sehingga penerimaan informasi lebih jelas dan mudah dipahami oleh anak. Pemberian terapi VEM juga dipraktekkan langsung oleh siswa sehingga meningkatkan minat anak dalam mengkonsumsi sayuran. Kegiatan bermain VEM ini memiliki manfaat yang besar dalam menunjang perkembangan kemandirian konsumsi anak. Karena dengan bermain Vegetable eating motivation (VEM) ini menyediakan waktu dan ruang bagi anak untuk belajar memahami mamfaat mengkonsumsi sayuran. Hasil penelitian lain menyimpulkan bahwa Identifikasi hasil dari konsumsi sayur sebelum diberikan pendidikan Kesehatan dengan metode storytelling di SDN Mulyoagung 04 Dau Malang memiliki nilai rata-rata (mean) 90,21 gram perhari dengan persentase $33,3 \%$ cukup (>150 gram perhari) dan $66,7 \%$ kurang $(<150$ gram perhari). Identifikasi hasil dari konsumsi sayur sesudah diberikan pendidikan Kesehatan dengan metode storytelling di SDN Mulyoagung 04 Dau Malang memiliki nilai rata-rata (mean) 128,71 gram perhari dengan persentase 70,8\% cukup ( $>150$ gram perhari) dan $29,2 \%$ kurang (<150 gram perhari). Ada perbedaan konsumsi sayur sebelum dan sesudah pendidikan Kesehatan dengan metode storytelling pada anak sekolah dasar di SDN Mulyoagung 04 Dau Malang (Suryandi, Hariyanto, \& Metrikayanto, 2018). 
Hasil penelitian juga menunjukkan masih terdapat 1 responden $(6,3 \%)$ yang tetap kurang mengkonsumsi sayuran setelah diberikan terapi VEM. Hal ini bisa disebabkan oleh beberapa hal seperti anak yang kurang serius dan antusias mengikuti kegiatan terapi bermain VEM. Anak juga kurang mendengar penjelasan yang disampaikan oleh peneliti sehingga anak tetap kurang suka mengkonsumsi sayuran. Berdasarkan hasil analisis uji paired t-test diperoleh nilai $\mathrm{t}$ hit $=8$,777 dengan taraf kepercayaan 95\% $(0,05) \mathrm{df}=15$ diperoleh $\mathrm{t}$ tabel $(1,753)$. Jadi $t$ hit $>t$ tabel dan $\mathrm{p}$ value $=0,000<0,05$ maka Ho ditolak dan Ha diterima berati ada pengaruh pemberian bermain vegetable eating motivation (VEM) terhadap perilaku makan sayur pada anak prasekolah di TK Asma Jaya Kabupaten Konawe Utara.

Hasil penelitian ini sejalan dengan penelitian menyimpulkan bahwa Hasil uji statistik didapatkan nilai rata-rata konsumsi sayur sebelum diberikan intervensi yaitu 38,22 dengan standar deviasi (SD) 18,236 dan setelah diberikan intervensi yaitu 68,11 dengan standar deviasi (SD) 18.304. Hasil analisa diperoleh $\mathrm{p}$ value sebesar $0,000<a(0,05)$, maka dapat disimpulkan terjadi peningkatan konsumsi sayuran pada anak prasekolah setelah diberikan terapi bermain Vegetable Eating Motivation (VEM) (Noviyanti emulyani, 2017). Penelitian ini juga sejalan dengan penelitian (Burhannudin Ichsan, Bayu Hendro Wibowo, 2015) bahwa hasil penelitian dengan mengggunakan uji $\mathrm{t}$ (deoendent $t$ test) dengan pendekatan pre test dan post tes diperoleh nilai p-value $=0,000(<0,05)$. Simpulannya yaitu terdapat peningkatan pengetahuan tentang pentingnya sayuran bagi anak-anak yang bermakna setelah mengikuti sesi penyuluhan.

\section{SIMPULAN}

Perilaku makan sayuran anak pra sekolah sebelum bermain Vegetable Eating Motivation (VEM) Di TK Asma Jaya Kecamatan Lasolo Kabupaten Konawe Utara sebagian besar yang memiliki nafsu makan kurang. Perilaku makan sayuran anak pra sekolah sesudah bermain Vegetable Eating Motivation (VEM) Di TK Asma Jaya Kecamatan Lasolo Kabupaten Konawe Utara sebagian besar nafsu makan cukup meningkat dibandingkan sebelum bermain Vegetable Eating Motivation. Ada pengaruh bermain Vegetable Eating Motivation (VEM) Terhadap Perilaku Makan Sayuran Pada Anak Prasekolah Di TK Asma Jaya Kecamatan Lasolo Kabupaten Konawe Utara $p<\alpha(\rho=0,000<\alpha=0,05)$.

\section{UCAPAN TERIMA KASIH}

Terima kasih penulis ucapkan kepada para pendidik TK Asma Jaya Kecamatan Lasolo Kabupaten Konawe Utara yang telah meluangkan waktunya untuk mengisi instrument penelitian ini dan semua pihak yang telah membantu pelaksanaan penelitian dan penulisan artikel ini. Tidak lupa ucapan terima kasih kepada editor dan reviewer Jurnal Obsesi yang sudah memberikan kesempatan sehingga jurnal bisa untuk diterbitkan.

\section{DAFTAR PUSTAKA}

Amirullah, A., Try, A., Putra, A., Daud, A., \& Kahar, A. (2020). Deskripsi Status Gizi Anak Usia 3 Sampai 5 Tahun Pada Masa Covid 19, 1(2), 16-27. https:// doi.org/doi.org/10.37985/murhum.v1i1.3

Anhusadar, L. (2016). Kreativitas Pendidik di Lembaga PAUD. Al-Ta'dib, 9(1), 76-93.

Anhusadar, L. O., \& Islamiyah, I. (2020). Kualifikasi Pendidik PAUD Sesuai Permendikbud Nomor 137 Tahun 2014. Journal on Early Childhood Education Research (JOECHER), 1(2), 55-61. https://doi.org/10.37985/joecher.v1i2.8

Arifin, Z. (2016). Gambaran Pola Makan Anak Usia 3-5 Tahun Dengan Gizi Kurang Di Pondok Bersalin Tri Sakti Balong Tani Kecamatan Jabon -Sidoarjo. Midwiferia, 1(1), 16. https:/ / doi.org/10.21070/mid.v1i1.345

Aswatini, Noveria, M., \& Fitranita. (2008). Konsumsi Sayur dan Buah di Masyarakat dalam Konteks Pemenuhan Gizi Seimbang. Jurnal Kependudukan Indonesia, 3(2), 97-119. https:// doi.org/bhp270 [pii] \r10.1093/cercor/bhp270 
Asy'ariyah, N. Z., Arief, Y. S., \& Krisnana, I. (2014). Storytelling sebagai upaya meningkatkan konsumsi sayur. Pediomaternal Nursing Journal, 3(1), 73-82. https://doi.org/10.20473/pmnj.v3i1.11768

Balitbang Kemenkes, R. I. (2013). Riset kesehatan dasar; RISKESDAS. Jakarta: Balitbang Kemenkes RI, 2013, 110-119.

Burhannudin Ichsan, Bayu Hendro Wibowo, dan M. N. S. (2015). Penyuluhan Pentingnya Sayuran Bagi Anak-Anak Di Tkaisyiyah Kwadungan, Trowangsan, Malangjiwan, Colomadu, Karanganyar. J.cnki.sgs, 29-35. https://doi.org/https://doi.org/10.13249

Damayanti, R. R., Ch, M., \& Hapidin, H. (2018). Pengaruh Bermain Peran Mikro terhadap Kecerdasan Interpersonal. Jurnal Obsesi : Jurnal Pendidikan Anak Usia Dini, 2(52), 34-43.

Hasanah, U. (2016). Pengembangan Kemampuan Fisik Motorik Melalui Permainan Tradisional Bagi Anak Usia Dini. Jurnal Pendidikan Anak, 5(1), 717-733. https://doi.org/10.21831/jpa.v5i1.12368

Hermina, H., \& S, P. (2016). Gambaran Konsumsi Sayur dan Buah Penduduk Indonesia dalam Konteks Gizi Seimbang: Analisis Lanjut Survei Konsumsi Makanan Individu (SKMI) 2014. Buletin Penelitian Kesehatan, 44(3), 4-10. https:/ / doi.org/10.22435/bpk.v44i3.5505.205-218

Ilya Krisnana, Yuni Sufyanti Arief, N. Z. A. (2015). Storytelling sebagai upaya meningkatkan konsumsi sayur. Pediomaternal Nursing Journal, 3(1), 53.

Indira, I. ayu. (2015). Perilaku Konsumsi Sayur Dan Buah Anak Prasekolah Di Desa Embatau Kecamatan Tikala Kabupaten Toraja Utara. Media Kesehatan Masyarakat Indonesia, 11(4), 253-262. https:// doi.org/10.30597/mkmi.v11i4.538

Kemenkes, R. I. (2014). Laporan Nasional Riset Kesehatan Dasar Tahun 2013. Jakarta: Badan Peneliian Dan Pengembangan Kesehatan.

KemenkesRI. (2016).

Situasi

Balita

Pendek. https://doi.org/10.1109/CSCMP45713.2019.8976568

Khalimatus Sa'diya, L. (2016). Hubungan Pola Makan Dengan Status Gizi Anak Pra Sekolah Di Paud Tunas Mulia Claket Kecamatan Pacet Mojokerto. Midwiferia, 1(2), 69. https://doi.org/10.21070/mid.v1i2.350

Kusharto, C. M. (2007). Serat Makanan Dan Perannya Bagi Kesehatan. Jurnal Gizi Dan Pangan, 1(2), 45. https:// doi.org/10.25182/jgp.2006.1.2.45-54

Laode Anhusadar, I. (2020). Penerapan Perilaku Hidup Bersih dan Sehat Anak Usia Dini di Tengah Pandemi Covid 19. Jurnal Obsesi: Jurnal Pendidikan Anak Usia Dini, 5(1), 463475. https:// doi.org/10.31004/obsesi.v5i1.555

Masganti Sit. (2015). Psikologi Perkembangan Anak Usia Dini. Medan: Kelompok Penerbit Perdana Mulya Sarana.

Notoatmodjo, S. (2012). Metodologi penelitian kesehatan. Jakarta: rineka cipta.

Noviyanti emulyani, malisa zahyani. (2017). Pengaruh Terapi Bermain Vegetable Eating Motivation ( Vem ) Terhadap Perilaku Makan, 1-11.

Nurdin, N., \& Anhusadar, L. O. (2020). Evaluasi Pelaksanaan Standar Proses di Satuan Pendidikan Anak Usia Dini. Jurnal Obsesi : Jurnal Pendidikan Anak Usia Dini, 4(2), 982. https://doi.org/10.31004/obsesi.v4i2.485

Rahmad, A. H. Al, \& Almunadia, A. (2017). Pemanfaatan Media Flipchart Dalam Meningkatkan Pengetahuan Ibu Tentang Konsumsi Sayur Dan Buah. Jurnal Kedokteran Syiah Kuala, 17(3), 140-146. https:/ / doi.org/10.24815/jks.v17i3.9062

Siti Aizah. (2003). Faktor-Faktor Penyebab Kesulitan Makan Pada Anak Usia Pra Sekolah Di Dusun Pagut Desa Blabak Kecamatan Pesantren Kota Kediri, (1), 6-8. https://doi.org/10.16309/j.cnki.issn.1007-1776.2003.03.004

Sujiono. (2015). Konsep dasar pendidikan anak usia dini, Jakarta.

Sukamti, E. R. (1994). Pengaruh Gizi Terhadap Pertumbuhan Dan Perkembangan Anak, 3(3), 139-153. https://doi.org/10.21831/cp.v3i3.9154 
Suriati, S., Kuraedah, S., Erdiyanti, E., \& Anhusadar, L. O. (2019). Meningkatkan Keterampilan Motorik Halus Anak melalui Mencetak dengan Pelepah Pisang. Jurnal Obsesi : Jurnal Pendidikan Anak Usia Dini, 4(1), 211. https:/ / doi.org/10.31004/obsesi.v4i1.299

Suryana, D. D. M. P. (2007). Dasar-Dasar Pendidikan TK. Hakikat Anak Usia Dini, 1, 1-65.

Suryandi, A., Hariyanto, T., \& Metrikayanto, W. D. (2018). Perbedaan Konsumsi Sayur Sebelum Dan Sesudah Pendidikan Kesehatan Dengan Metode Storytelling Pada Anak Sekolah Dasar Di Sdn Mulyoagung 04 Dau Malang. Nursing News, 3(1), 237-246.

Udu, S., Anhusadar, L. O., Alias, A., \& Ali, L. (2019). Hedole Dole : Stunting Tradisional Masyarakat Wakatobi. Al-Izzah: Jurnal Hasil-Hasil Penelitian, 14(2), 32. https:// doi.org/10.31332/ai.v14i2.1508

Wahyuni, T., Syukri, M., \& Halida. (2017). Peningkatan motivasi anak makan sayuran melalui metode bermain permainan cooking class pada anak usia 5-6 tahun, 1-11. 